\title{
Research analysts at the City of Boroondara: the many hats
}

\author{
Tanya Styles ${ }^{\mathrm{a}}$ \\ ${ }^{a}$ Community Planning and Development, City of Boroondara, \\ tanya.styles@boroondara.vic.gov.au
}

\begin{abstract}
Local government is the tier of government that works most closely with the community it serves. A sound understanding of the local community is critical to local governments in the development of relevant and responsive strategies, plans and policies. The range of data sources available to facilitate such understanding is immense, and council departments benefit from access to timely analysis of relevant data to inform their work. The City of Boroondara's Social Planning Unit employs two research analysts who act as a central resource for council; identifying, collecting and analysing data about the community. The information is then disseminated in a variety of formats throughout Council and to the community. This paper provides details of five projects which highlight the work of the City of Boroondara's research analysts and outlines how their work is applied by Council staff and the community. It also highlights the range of research requests that make up the officers' day to day work, and how these inform strategic planning and service delivery. Lastly, the paper makes comment on how the location of the research analysts in the Community Development Directorate offers a unique opportunity to inform policy across the organisation. It is hoped that the information contained in this paper will promote ideas about the dissemination and application of readily available data sources among local government staff, councillors and the community.
\end{abstract}

\begin{abstract}
Aim
This paper presents examples of projects undertaken by the research analysts at the City of Boroondara including, in some cases, lessons learned from these projects. The paper is aimed at promoting ideas about how socio-demographic data might be used by officers in other Councils.
\end{abstract}

\section{Background}

The City of Boroondara is comprised of 12 inner eastern suburbs of Melbourne and covers an area of 60 square kilometres. The municipality is home to an estimated 
167,977 people (ABS 2013a). Population features vary considerably across the municipality, notably in terms of the prevalent age and cultural groups.

The City of Boroondara employs two research analysts (1.8 EFT). Both work within the Social Planning Unit of the Community Planning and Development Department, which has a diverse assortment of responsibilities that include:

- policy, plan, and strategy development (health, cultural diversity, access and inclusion, gaming, Indigenous culture and heritage, and social housing)

- administering the Annual Community Development Grants Program

- managing the Boroondara Volunteer Resource Centre

- supporting Boroondara's ten neighbourhood houses

- advocacy on a range of issues such as community safety, family violence and affordable housing

- providing skills development and networking opportunities to the local community sector.

The City of Boroondara employs approximately 1,000 staff working in 23 departments in four directorates. The research analysts work within the Community Development Directorate, which is focussed generally on policy development and external program and service provision (rather than internal service provision). The location of Boroondara's research analysts in relation to the Community Development Directorate is depicted in Figure 1.

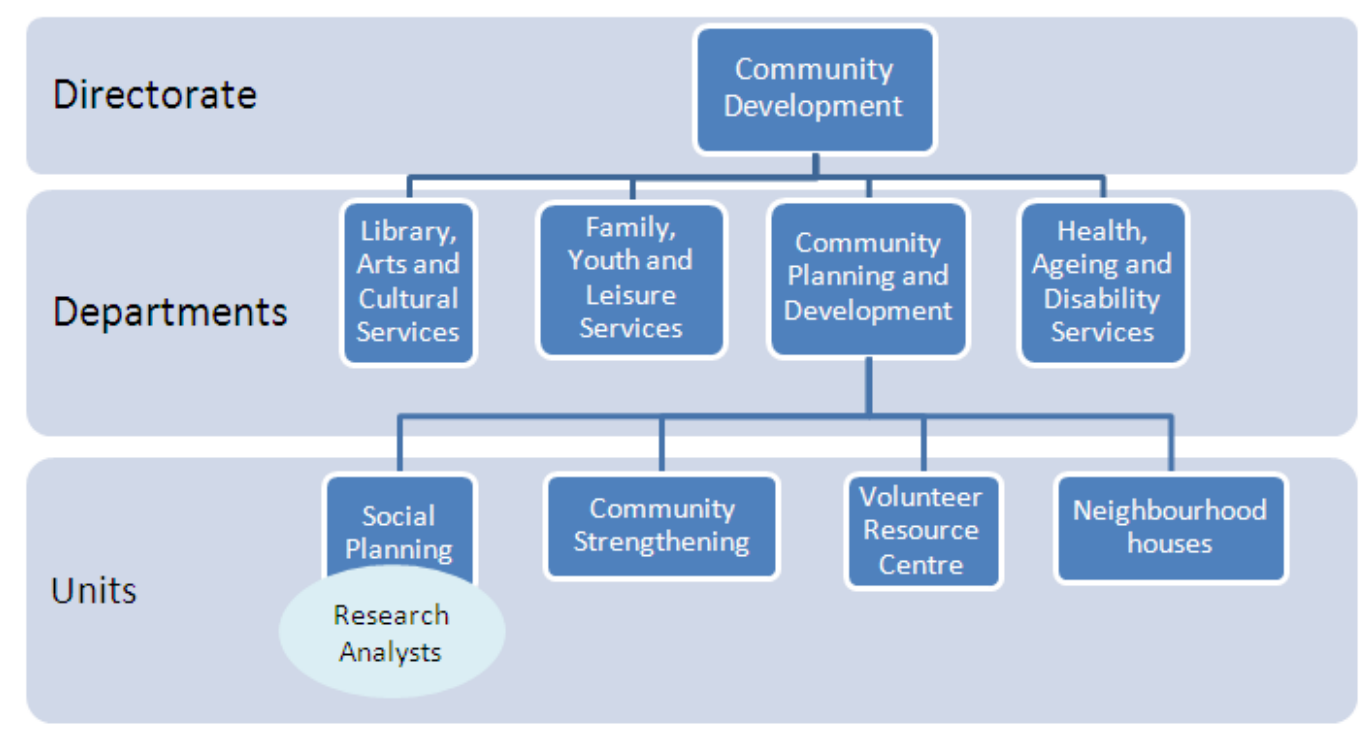

Fig. 1. Location of research analysts within the Community Development Directorate 
The research analysts’ primary responsibilities are:

- the collection and analysis of social, health and demographic data, to assist the planning, policy development and service delivery functions of Council departments

- the provision of advice on appropriate research and evaluation techniques, including survey design and results analysis

- the management of Council's online demographic profile and population forecast tools (produced by .id Consulting)

- the maintenance and ongoing improvement of the Boroondara Social Profile (a publicly available online compilation of social, health and demographic data pertaining to the Boroondara community), Boroondara's Community Services and Facilities Database (a listing which encompasses 47 service and facility categories and can be used to assist in the identification of service gaps), and the Community Information Clearinghouse (see section 'Projects and informing policy').

Information dissemination is achieved partly through 'request work', whereby Council staff request information about the local community or advice on research projects. Requests from residents or community groups are also accommodated, but tend to be more limited in scope.

Through performing the functions described above, the research analysts act as a central resource for the rest of Council and the community. Their work serves to enhance the quality of the evidence base for Council activities and helps to ensure the consistency of the socio-demographic data being used across Council projects.

The research analysts act to build Council staff's capacity to apply readily accessible information sources such as the .id Profile, ${ }^{1}$ but many projects require complex analyses, the combination of a range of data sources, and a thorough understanding of the strengths and limitations of each source. Maintaining research analyst capacity within Council serves to reduce Council's reliance on external consultants for research and data analysis activities and means that research capabilities are built alongside knowledge of the organisation and the local community.

The location of the research analysts within the Community Development Directorate provides important opportunities for collaboration. The Community Development Directorate includes several working units that are responsible for focussing on the needs of a particular demographic segment of the community, for example older residents, or

\footnotetext{
${ }^{1}$ See $<$ http://profile.id.com.au/boroondara/home> .
} 
families with young children. Data sources like the Census of Population and Housing and population forecasts can be powerful tools for appropriately targeting initiatives that are aimed at a population subgroup and for identifying emerging trends and issues that are important for responsive policy and service development.

\section{Promotion and capacity building}

Promoting the availability and potential uses of socio-demographic data across Council has become a core part of the research analysts' role. The research analysts are familiar with a range of data sources that can be valuable to many different Council departments and, as such, they serve as a central resource for the collation and dissemination of this information.

Internal promotion of the request work services offered by the research analysts is crucial to ensuring that Council is able to capitalise fully on their role. Promoting their services also assists to raise the status of the work performed by the research analysts, which often feeds into large and high-profile projects but is rarely presented in standalone form. The large projects to which the research analysts have contributed include the Boroondara Activity Centres Strategy ${ }^{2}$ and the Draft Boroondara Open Space Strategy. ${ }^{3}$

Some socio-demographic and health data is readily available online and designed to be interpretable by an audience with limited background knowledge of the data source or of statistics. The promotion activities described in this paper incorporate a component of capacity building to assist staff access and apply such data.

\section{Promotion activities}

The Know Your Community newsletter and the Social Planning Unit road show are ongoing initiatives aimed at promoting the research analysts' services and at staff capacity building.

The Know Your Community newsletter (Figure 2) is published biannually and produced entirely by the research analysts. The newsletter is limited to a double-sided A4 page and typically includes three or four articles and two regular features. Articles are always locally focussed and usually highlight a newly released data source, providing basic methodological information and highlighting some key results. Wherever possible, website addresses are provided to enable readers to further explore the data sources

\footnotetext{
${ }^{2}$ See <http://www.boroondara.vic.gov.au/your_council/building-planning/strategicplanning/plans/acs $>$.

${ }^{3}$ See <http://www.boroondara.vic.gov.au/your_council/building-planning/strategicplanning/plans/open-space-strategy>.
} 
described. The newsletter always begins by providing the research analysts' contact details.

The newsletter is circulated via email to Council's Senior Management Group, Team Leaders and Coordinators. A version of the newsletter is also posted on the Council website and sent to a network of local community groups and service providers.
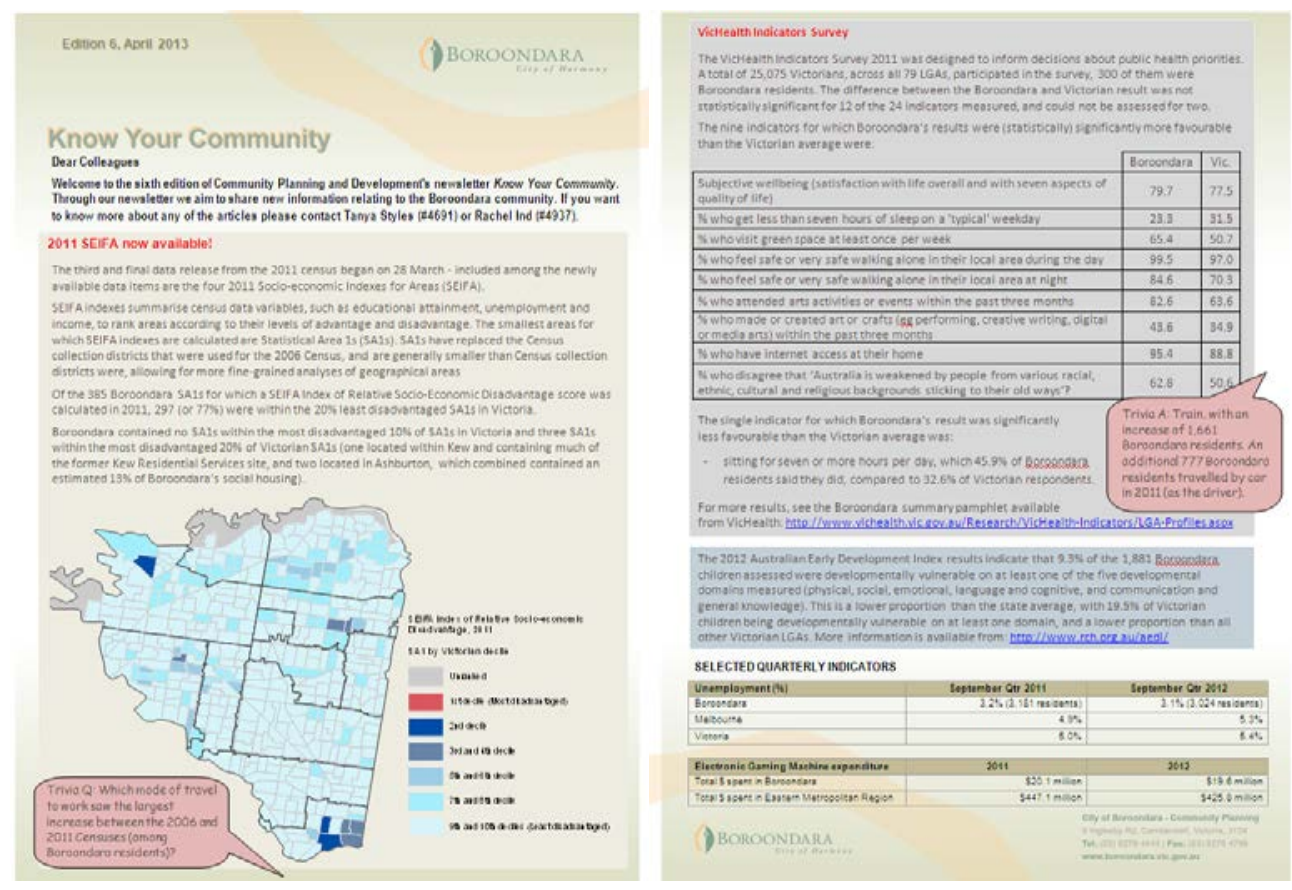

Fig. 2. The April 2013 edition of Know Your Community

The Social Planning Unit road show is a program of team visiting. A full list of the City of Boroondara's policies, plans and strategies was used to identify work units with which the research analysts did not already have strong links. Arrangements are made with coordinators or team leaders for a research analyst to attend a team meeting to deliver a presentation outlining freely available data sources that staff can access themselves, and on the request work service offered.

The presentations are customised to reflect the foci of the respective work unit, but in each case are aimed at capacity building as well as promotion. Data sources covered in all presentations include:

- the City of Boroondara's online population profile tool (produced by id Consulting)

- the City of Boroondara's online population forecast tool (produced by .id Consulting) 
- the City of Boroondara's Community Information Clearinghouse (see section 'Projects and informing policy')

- the Australian Bureau of Statistics' Census website.

\section{Promotion outcomes}

The Know Your Community newsletter and Social Planning Unit road show have not been formally evaluated. Since these promotion projects commenced in 2010, the number of request work projects completed has increased considerably. For example, in 2011-12 the research analysts completed 176 requests (the majority of which took between 30 minutes to four hours to complete). The 2011-12 figure represented an increase of $90 \%$ over 2009-10 in the number of requests completed (the research analysts having become victims of their own popularity!)

The increase in requests arguably reflects an increase in the awareness of sociodemographic data and its uses in guiding the work of Council. As well as the various promotion activities undertaken, staff are aware that Boroondara councillors value evidence-informed recommendations. The observed increase in request work projects may also partially reflect a shifting of work to the research analysts from other officers, which may have efficiency benefits.

\section{Projects and informing policy}

\section{The Community Information Clearinghouse}

The Community Information Clearinghouse is a central point from which Council staff can access information about the local community. The Clearinghouse is designed to be the first place Council officers look when planning a research project or conducting policy background investigations. It is aimed at minimising the time that Council staff have to spend in identifying and gaining access to documents for such purposes, preventing the duplication of research, and promoting the sharing of information across departments.

\section{Clearinghouse activities}

The Community Information Clearinghouse was developed in early 2011 in consultation with staff in several departments who are now responsible for the ongoing contribution of content relevant to their area of work. Launched in August 2011, the Clearinghouse provides access to Council policies, strategies and research reports, as well as key policy documents, research, and guidelines published by other local governments, local government bodies, non-government organisations, peak bodies and 
the Victorian and Australian Governments. The Clearinghouse originally covered six topic areas:

- early years

- youth

- older age

- disability

- cultural and linguistic diversity

- $\quad$ service research (for example community satisfaction surveys).

The Community Information Clearinghouse is accessible to Council staff via the intranet. The user first selects the topic of interest from the Clearinghouse home page, and then the type of document of interest (for example Council documents, or other policies, strategies and frameworks). Once an item of interest has been located, the user is presented with an abstract which enables them to decide whether or not to download the associated document.

\section{Community Information Clearinghouse review}

The Clearinghouse was reviewed approximately six months after it was first introduced. Based on the results of a staff survey, as well as informal staff feedback, two additional topic categories were added to the Clearinghouse ('housing' and 'Indigenous'). Future work will focus on:

- increased promotion of the Clearinghouse

- facilitating ongoing contributions

- adopting an auditing process to enhance user confidence in the currency of the content

- simplifying the access process (that is, removing the 'type of document' level so that all titles within a topic area can be viewed at once).

\section{A funding application}

Council provides funding for a range of services and agencies. In 2013, Council prepared a joint funding submission to the Victorian Government with one of the agencies.

\section{Funding application activities}

The City of Boroondara supplemented the funding submission with detailed data about disadvantage in the precinct in which the agency is located. This data strengthened 
the demonstration of need for funding by highlighting the presence of disadvantage in what is, generally speaking, an affluent precinct.

\section{Home $>$ Work support $>$ Research and engagement $>$ Clearinghouse \\ Community Information Clearinghouse}

Have you wondered what research has previously been done in Council on a specific topic or about a population group?

Do you need evidence for a submission, report or policy?

Would you like to access a list of external websites about a particular topic?

The Community Information Clearinghouse is a tool where staff can access research, information and a list of further resources about particular service groups in the Boroondara community.

Early years - the $0-8$ years population of Boroondara.

Young people - the 12-25 years population of Boroondara

Older adults - older residents 65 years and over.

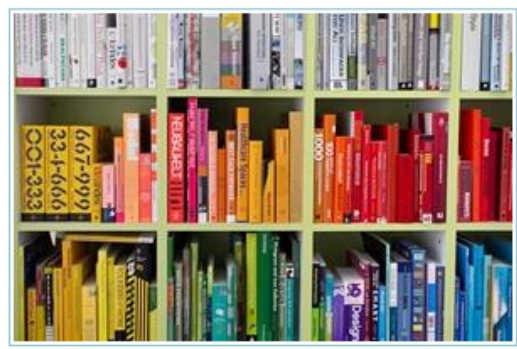

Disability - disability in the community

$\underline{\text { CALD }}$ - residents that have a cultural and linguistic diverse background

Indigenous - Residents with Indigenous backgrounds.

Housing-information on housing related issues.

Service research - research reports about the services Council provides.

Fig. 3. The home page of the Community Information Clearinghouse

The precinct is characterised by a high concentration of tertiary students, including international students, and it also contains a substantial proportion of Boroondara's social housing. The Australian Bureau of Statistics' Socio-Economic Indexes for Areas (SEIFA) data (ABS 2013b, ABS 2013c) was used to highlight concentrations of economic disadvantage in parts of the precinct. Geographic information systems (GIS) software was used to depict the SEIFA data with maps and demonstrate the apparent correlation between economic disadvantage and the location of student residences and social housing. The characteristics of residents of the most economically disadvantaged areas within the precinct (depicted in red and dark blue in Figure 4) were examined, to reveal that a high proportion (24\%) were relatively recent arrivals (less than six years) to Australia.

The high concentration of social housing in the precinct of interest (which, for example, contains $40 \%$ of Boroondara's known rooming house beds but only $22 \%$ of Boroondara's population) compared to much of the rest of the municipality was demonstrated using Census data and Council's rooming house register. Lastly, the large number of overseas students attending tertiary campuses in the precinct was highlighted using published enrolment statistics. 


\section{1 rooming house survey}

The City of Boroondara is, as noted, generally speaking an affluent area and was highest ranked of all Victorian local government areas on the Australian Bureau of Statistics’ Index of Relative Socio-economic Advantage and Disadvantage (ABS 2013d). Nonetheless, Boroondara has scattered disadvantage as well as pockets of disadvantage, the latter often associated with tertiary student residences and/or social housing.

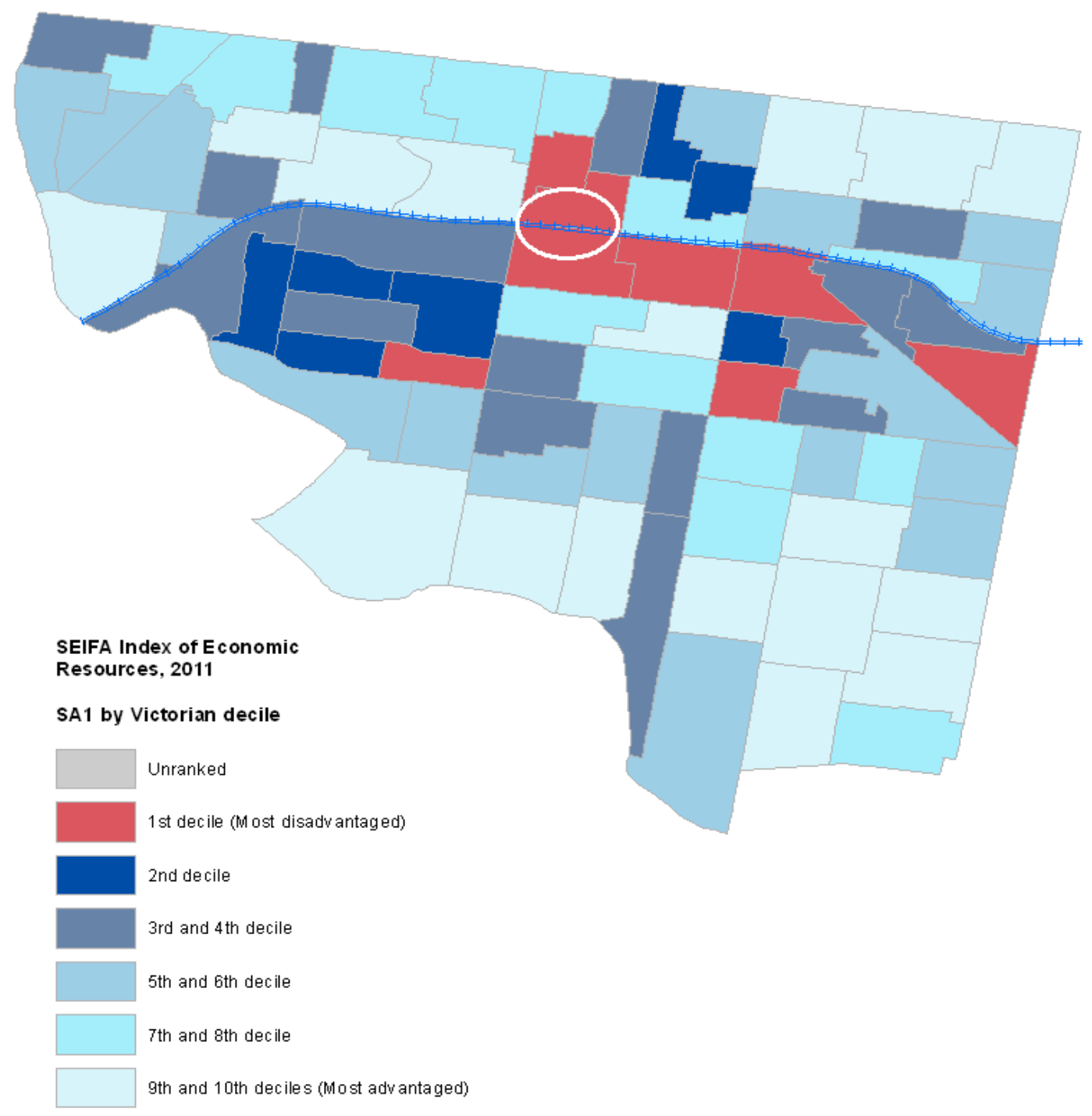

Fig. 4. 2011 SEIFA Index of Economic Resources, re-opened neighbourhood house precinct (university campus circled in white)

The more that is known about residents who are experiencing disadvantage, the easier it is for Council and other local services to provide appropriate support. Anecdotal evidence suggested that a shift had occurred in the demographic makeup of rooming house residents with a greater proportion being tertiary students and/or single women 
with children. The 2011 Rooming House Survey was aimed at collecting information about the operation of, and tenants living in, known rooming houses in the City of Boroondara.

\section{Rooming house survey activities}

The survey was developed by a research analyst and social planning officer in consultation with internal and external stakeholders, and included questions about the demographic characteristics of rooming house residents, referral sources and rental fees. An effort was made to ensure that the survey assisted Council to build a relationship with rooming house operators, rather than appearing to be a regulatory activity. To this end, the survey included:

- an offer of further information on the Boroondara Registered Rooming House Subsidy, which is offered by Council to private rooming house operators for oneoff safety and wellbeing projects, equipment purchases and ongoing maintenance

- a reminder about the biannual rooming house lunch that is hosted by the Council to provide a forum for discussion about issues relevant to the rooming house accommodation sector in the municipality.

The survey was mailed to all known rooming house operators. Follow-up letters and phone calls where possible, were used to achieve a response rate of 68\% (23 rooming houses).

\section{Rooming house survey outcomes}

The 2011 Rooming House Survey revealed that more than half of the rooming houses surveyed housed students. In more than $40 \%$ of the surveyed rooming houses, at least one-in-four residents was female, and at least one-in-three residents was of a non-English speaking background in over $50 \%$ of the surveyed rooming houses. A total of 11 rooming house residents were reported as being aged under 15 years.

As a result of experience gained during the conduct of 2011 Rooming House Survey, future Rooming House Surveys will:

- include space for operators to comment on important issues such as mental health, not otherwise covered by survey questions

- include questions about what rental payments cover (e.g. a whole room or just a bed)

- be distributed to ‘de-facto' rooming houses, such as hotels. 
A summary of the results of the 2011 Rooming House Survey was distributed to local housing support services to provide them with evidence of the changing demographic characteristics of rooming house residents. The Rooming House Survey will be repeated in 2013 and the results of the 2011 and 2013 Rooming House Surveys will be used as part of a revised Boroondara Social Housing Plan.

\section{Small request work projects}

Most request work projects are completed by the research analysts within a few hours. The following are four brief examples of the research requests that make up much of the research analysts’ day-to-day work.

\section{A project to encourage walking}

Boroondara's Principal Pedestrian Network Demonstration Project, currently in its planning phase, is aimed at encouraging local residents to walk rather than drive short trips to the Camberwell Activity Centre. Census data has been used to profile the population living in the immediate vicinity of the Centre, with a focus on older residents and families with school age children. In conjunction with community consultation, the population profile will be used to ensure that the actions implemented throughout the project are tailored to the local community.

\section{A grant application}

A number of improvements are being progressively implemented as part of the City of Boroondara's H. A. Smith Reserve Masterplan. Council's Business Development Department applied for funding through the 2012-13 Community Facility Funding Program offered by the Victorian Department of Planning and Community Development to build a beginners' skate and BMX playground in the reserve. Information on housing density, school enrolments, and resident populations of children and youth was incorporated into the application to assist in highlighting the need for the playground in the area. The application was successful and the playground, to be completed by the end of 2013, will give primary school aged children the opportunity to learn to ride and skate in a comfortable environment.

\section{University of the Third Age (U3A)}

The City of Boroondara has two U3A campuses which provide courses presented by volunteer tutors for people who have retired or are not in full-time work. Demographic profiles and population forecasts for suburbs of particular interest to U3A have been 
provided to the Management Committee to assist the organisation with its program planning.

\section{Prospective business operators}

Boroondara's local economy is based substantially on the service sector, including professional, scientific, financial, education and health services. Council's research analysts have provided demographic profiles to prospective business operators to use in guiding decisions about suitable shop-front locations, and to current business operators to use in guiding decisions about suitable products and programs. For example, a local health studio was provided with population figures by gender, age group, and by language spoken at home (based on the 2011 Census) for residents living within a 500 metre radius (approximately) of the business address.

\section{Conclusions and future directions}

Research analysts working in local government have an opportunity to wear 'many hats'. They can be collators of information in accessible forms, such as the Community Information Clearinghouse. They can assist with data gathering projects which improve understanding of emerging trends within the local community, such as the 2011 Rooming House Survey. They can play a role in securing funding for initiatives that benefit the local community, such as the H. A. Smith Reserve skate and BMX playground. They can help community organisations, like U3A, to obtain a clearer picture of population characteristics and trends that may assist in planning.

At the City of Boroondara, promotion has proven to be an important part of the research analysts' role. Making others within the organisation aware of the data analysis and research advice services offered by the research analysts enables staff across the organisation to consider how their own work might be supported by such assistance. The City of Boroondara's research analysts also promote their work as a means of elevating the importance of evidence-based planning and programming within the organisation and the community.

It is increasingly well recognised that, despite being a generally affluent area, Boroondara includes what have been termed 'pockets' of disadvantage. Council invests substantial time and resources to ensure that the needs of disadvantaged residents in these pockets are not overlooked. The Rooming House Survey and the funding application described in this paper are examples. While continuing this work, the Social Planning Unit, guided by the research analysts, is now embarking on a work program to gain a better understanding of scattered disadvantage within the municipality. That is, 
disadvantage that exists outside of the identifiable pockets. This project represents an exciting opportunity for the research analysts to wear perhaps their most important hat, that of learner.

\section{References}

Australian Bureau of Statistics (ABS) 2013a, 'Table 2: population estimates by local government area, 2011 to 2012', in Regional population growth, Australia, 2011-12, cat. no. 3218.0, ABS, Canberra, viewed 9 May 2013, <http://www.abs.gov.au/ AUSSTATS/abs@.nsf/DetailsPage/3218.02011-12?OpenDocument>.

ABS 2013b, 'Table 3: statistical area level 1, indexes, SEIFA 2011', in Census of Population and Housing: Socio-Economic Indexes for Areas (SEIFA), Australia, 2011, cat. no. 2033.0.55.001, ABS, Canberra, viewed 17 April 2013, <http://www.abs.gov.au/AUSSTATS/abs@.nsf/DetailsPage/2033.0.55.0012011?Ope nDocument $>$.

ABS 2013c, 'Table 4: statistical area level 1, indexes, SEIFA 2011', in Census of Population and Housing: Socio-Economic Indexes for Areas (SEIFA), Australia, 2011, cat. no. 2033.0.55.001, ABS, Canberra, viewed 17 April 2013, <http://www.abs.gov.au/AUSSTATS/abs@.nsf/DetailsPage/2033.0.55.0012011?Ope nDocument $>$.

ABS 2013d, 'Table 2: local government area, indexes, SEIFA 2011', in Census of Population and Housing: Socio-Economic Indexes for Areas (SEIFA), Australia, 2011, cat. no. 2033.0.55.001, ABS, Canberra, viewed 9 May 2013, <http://www.abs.gov.au/AUSSTATS/abs@.nsf/DetailsPage/2033.0.55.0012011?Ope nDocument>. 